\title{
State dispositions in social judgment
}

\author{
MARTIN F. KAPLAN \\ Northern Illinois University, DeKalb, Illinois 60115
}

\begin{abstract}
Social judgment is a joint function of judge disposition and stimulus information. Dispositions may take the form of enduring traits or of transient states. This experiment was aimed at establishing the extent of correspondence between dispositional traits and states in their effects on judgments of stimulus persons. States were induced by optimistic or pessimistic news broadcasts. Subjects evaluated a confederate who predominantly agreed or disagreed with them on either three or six attitudinal issues. Induced states affected judgments of others, but the pattern of interaction with stimulus cues (others' attitudes or descriptions) differed from that shown in earlier studies of dispositional traits. As in studies using trait-derived dispositions, the effect of state dispositions was uniform across different valences of stimulus information. Unlike the case with trait dispositions, states did not decrease in impact with larger amounts of information. States and traits of the judge cannot therefore be considered conceptually equivalent in their role in social judgment.
\end{abstract}

Individuals have been known to differ in their tendencies to judge others positively or negatively for some time (Asch, 1946; Gage \& Cronbach, 1955). Means of assessing these evaluative tendencies independently of social judgments were developed by Kaplan (1976), who found such "global dispositions" to be relatively stable over time. A consistent finding is that people with global dispositions to judge others positively rate a variety of stimulus persons more favorably than do people with negative dispositions (Kaplan, 1972, 1973, 1975). However, the magnitude of dispositionally based differences in judgment is not constant. Rather, conditions that allow the perceiver to rely more on the characteristics of the particular stimulus person serve to diminish the impact of a priori dispositions. When information about the stimulus person is more (1) abundant (Kaplan, 1971b, 1971c, 1972), (2) internally nonredundant (Kaplan, 1972), (3) internally consistent (Kaplan, 1973), (4) reliable as to source (Kaplan, 1971a, 1971b; Kaplan \& Miller, 1978), or (5) relevant to the judgment dimension (Kaplan, 1971c), dispositions are less likely to affect judgment of a particular stimulus person than when otherwise.

These findings are consistent with an interactionist position in personality theorizing. Reviews of personality research (e.g., Ekehammar, 1974; Endler \& Magnusson, 1976) have concluded that neither trait dispositions nor external situational or stimulus conditions alone can adequately account for behavior. Instead, empirical results favor the conclusion that trait dispositions exert differential impact on responses, depending on the situation. This appears to be the case when considering the interaction of personological dispositions in judging others and informational constraints (Kaplan, 1976).

Requests for reprints should be sent to the author at the Department of Psychology, Northern Illinois University, DeKalb, Illinois 60115 .
Global dispositions refer to relatively enduring tendencies to evaluate others in certain ways. Consider, for example, Ebenezer Scrooge's pre-Christmas tendencies to evaluate others negatively (Dickens, 1843) or Pollyanna's (Porter, 1913) positive inclinations. As such, dispositions can be considered traits in the judge, or residuals of past experience with other people. Prejudgmental dispositions may also be induced as transient states in the individual. For example, obnoxious behavior by trial attorneys (Kaplan \& Miller, 1978), crowding (Griffitt \& Veitch, 1971), physical discomfort (Griffitt, 1970), noise (Kenrick \& Johnson, 1979), and pessimistic radio broadcasts (Veitch \& Griffitt, 1976) have all been shown to affect social judgments. Although induced states are manipulable by temporary conditions and represent transient dispositions (often labeled "moods"), they may serve in the same manner as trait dispositions. That is, they too promote a predispositional state in the judge that combines with stimulus-related information to produce the judgment of the stimulus person. Whether the effects of temporary state dispositions parallel the effects of trait dispositions in judgment formation was studied here. In previous studies, the impact of positive or negative trait dispositions was constant for different levels of positivity of person stimuli but was lessened for increased amounts of stimuli. That is, positive-dispositioned subjects are more positive in their judgments of positively and negatively described stimulus persons than are negative-dispositioned subjects, and equally so in both cases, but the differences are progressively reduced when more information is provided (Kaplan, 1971b, 1971c, 1972, 1976).

\section{METHOD}

\section{Overview}

Subjects overheard a contrived radio broadcast designed to induce positive, neutral, or negative state dispositions. They then judged a confederate who primarily agreed or disagreed with the subject on either three or six attitude items. 


\section{Subjects}

Initially, 133 introductory psychology students from Northern Illinois University volunteered for the experiment to earn extra course credit. Thirteen of these subjects were discarded due to suspicions regarding experimental deceptions. The remaining 120 subjects were equally divided among 12 experimental conditions. In each condition, there were four males and six females.

\section{Stimulus Materials}

Six attitude topics were selected to represent a broad range of interest and importance for students. For each topic, three "pro" and three "con" statements were obtained from relevant attitude scales (Shaw \& Wright, 1967). Audiotapes were constructed in which a confederate read an assertion for the topic (e.g., "There should be one national presidential primary instead of the present system of several statewide primaries"), then reported his agreement or disagreement, and, finally, gave three statements supporting his attitude. For each assertion, one tape track contained agreements and the other contained disagreements.

\section{Procedure}

Three independent variables were manipulated: state disposition, proportion of subject-confederate attitude agreement, and number of attitudes expressed by the confederate. The subject was seated in the experimental room and given consent and experimental credit forms to complete. The experimenter explained that the experiment involved a second subject, waiting in another room, and excused himself in order to give the other subject his instructions. On the way out of the room, the experimenter nonchalantly turned on a radio located on a shelf behind the subject, saying that the subject might want to hear some music while waiting. This activated one of three tape recordings, played through the radio speaker. For all three disposition conditions, the tape began with the last $15 \mathrm{sec}$ of a "Top 40" hit. In the control condition, this was followed by another song of the same duration as the messages in the experimental conditions. In the positive-disposition condition, a professional radio announcer introduced a fictional syndicated commentator with a daily feature of the station (conveniently located in Iowa) titled "A look at our world." The commentator painted humankind in a rather positive light, as creatures who overcome all sorts of adversities posed by a cruel environment to triumph in the end. In the negative-disposition condition, the commentator recounted the wicked deeds in humanity's past and present history (essentially, the same "adversities" as in the positive condition), portraying people as nasty creatures, responsible for their predicament. A commercial followed the propaganda (or music), and this was the cue for the experimenter's return. The experimenter verbally elicited the subject's response to the radio presentation to determine whether the subject had attended to the propaganda or had suspected its authenticity. Only 4 subjects, of 133 tested, were discarded at this point due to suspiciousness or inattention.

Subjects were told that the experiment was concerned with methods of opinion polling. They were to be polled by another subject on six opinion topics. After each topic was read to them by the pollster in the next room, they were to agree or disagree with the statement, giving a brief reason for their response. Following each response, the pollster was to give his own response, in the same manner. The alleged purpose of this was to see how successful opinion polling would be if untrained pollsters reported their own attitudes to interviewees. Half of the subjects were told that the pollster was instructed to respond to all six items but that some other subjects would be privy to only three of the pollster's attitudes (Set Size 6). The remaining subjects were told the pollster could respond to only three of the six items, although some other subjects would be in a condition in which all six were answered (Set Size 3). The three items in the latter set-size condition were randomly selected for each subject, and the subject was informed of this. The purpose of these instructions was to maximize salience of the single set size each subject received. All subjects gave their attitudes to all six items.

For each attitude item, the pollster's responses were selected so that he was in agreement or disagreement with the subject on two-thirds of the items. Half the subjects in each set size by disposition cell encountered agreement, and half received disagreement.

To summarize the design, there were 12 treatment conditions based on manipulated disposition (positive, negative, or control), set size (three or six), and proportion of agreement (.33 or .67). A posttreatment questionnaire embedded two dependent measures among items related to poll taking. The first consisted of two items from Byrne's (1971) Interpersonal Judgment Scale (IJS), relating to liking for the pollster and desirability as a work partner. The subject selects an alternative for each item, indicating the extent of liking and desirability, and the responses are summed to yield an attraction score ranging from 2 to 14 . The second dependent measure was a $120-\mathrm{mm}$ line, with endpoints labeled "Dislike very much" and "Like very much," on which the subject had to mark the point representing his or her feelings about the pollster.

After completion of the questionnaire, a structured interview was held, both to debrief the subject and to assess awareness of the true purpose of the experiment or of the deceptions employed. Nine of the remaining 129 subjects were discarded due to suspicions that the pollster's responses were contrived. Four of these were subjects who had been students in an introductory psychology section taught by the confederate and who had recognized his voice.

\section{RESULTS}

Mean attraction scores for the IJS measure are presented in Figure 1. Clearly, positive stimuli led to greater attraction, and positive propaganda resulted in more attraction toward the pollster than did negative propaganda. The latter finding is interesting in that it demonstrates that induced dispositions toward people in general affect the response to specific others.

Note the divergence of the curves for positive and negative stimuli in all three panels. Divergence gives evidence of a set-size effect; attraction based on negative stimuli became more negative, and attraction based on positive stimuli became more positive, with an increase in set size.

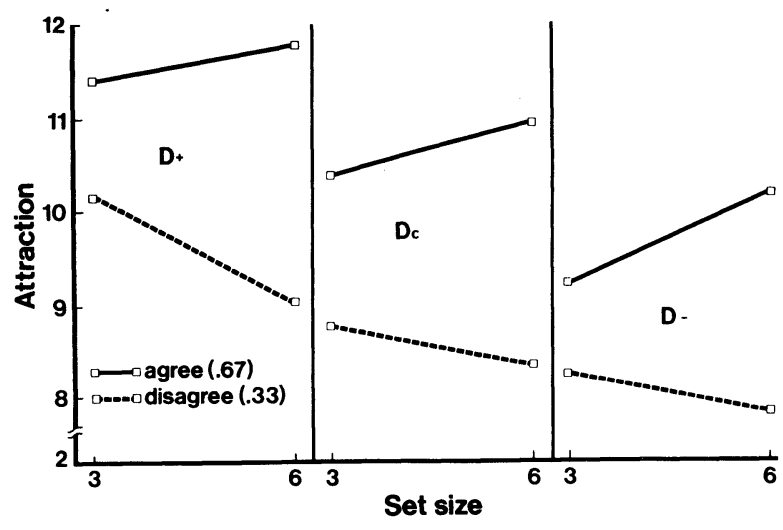

Figure 1. Attraction as a function of number and proportion of agreeing attitudes and state disposition (D) of subjects. 
The pattern of mean likableness scores closely paralleled the pattern of mean IJS attraction scores.

To test the reliability of these observations, an analysis of variance was performed on the complete design. For the data in Figure 1, the effects for proportion of agreement $[F(1,108)=4.53]$ and for state disposition $[F(2,108)=11.43]$ were both significant (ps <.05). The set-size extremity effect is tested by the Set Size by Proportion of Agreement interaction, which was significant $[F(1,108)=5.04, p<.05]$. No other effects reached significance (all $\mathrm{Fs}<1$ ). A similar pattern was true for likableness ratings. Effects of proportion of agreement $[\mathrm{F}(1,108)=4.97]$ and state disposition $[\mathrm{F}(2,108)=14.73]$ were significant (ps $<.05$ ), as was the Set Size by Proportion of Agreement interaction $[F(1,108)=7.12, p<.05]$. In short, across all stimulus persons and for both dependent measures, state dispositions affected positivity of response and responses were more extreme when more attitudes were shared. Dispositional effects were independent of both amount and agreement level of shared attitudes.

\section{DISCUSSION}

Impressions are not based only on information known about the person being judged. The present study helps show that evaluative dispositions can affect judgments. These dispositions can exist as trait tendencies-the relatively enduring residuals of past experience with people (see also Kaplan, 1972, 1973, 1975, 1976)-and as transient mood states in the individual. In addition to the propaganda manipulations employed here, dispositional states may also be induced by variations in such diverse conditions as population density (Griffitt \& Veitch, 1971), temperature (Griffitt, 1970), noise level (Kenrick \& Johnson, 1979), and expectations (Kelley, 1950). Irrespective of the source of the disposition, individuals with positive dispositions tend to make more favorable judgments of others than do people with negative dispositions.

Despite their different antecedent conditions, trait and state dispositions are functionally similar in the sense that both affect evaluative responses in a constant manner across evaluative levels of information. However, closer scrutiny considering contextual parameters reveals important differences in how traits and states affect judgments. When trait dispositions are considered, the polarizing effects of set size are greater for positive-disposition subjects when the stimulus information is negative, but they are greater for negative-disposition subjects when the stimulus information is positive (Kaplan, 1972). In other words, the set-size extremity effect appears to be enhanced for stimuli further removed from the prejudgmental disposition. This experiment, however, failed to obtain any interactions of disposition with set size when dispositions represented induced states.

Research in other realms of personality has shown the need for distinct conceptualizations of traits and states (e.g., see Spielberger, 1975, for distinctions between state and trait anxiety). It could be, for example, that states have a more immediate and forceful impact upon behavior and, thus, are less amenable to amelioration by other situational variables. That is, the greater salience of dispositional states, compared with traits, makes them more likely to be manifested in judgment even when a larger set of information is available.

The present studies suggest that different theoretical processes may have to be postulated to explain the operation of state and trait dispositions. Research that systematically and simul- taneously varies state dispositions, trait dispositions, and stimulus information will allow us to understand the judgment formation process more fully.

\section{REFERENCES}

Asch, S. Forming impressions of personality. Journal of Abnormal and Social Psychology, 1946, 48, 258-290.

Byrne, D. The attraction paradigm. New York: Academic Press, 1971.

Dickens, C. A Christmas carol in prose. London: Chapman \& Hall, 1843.

ЕкенаммаR, B. Interactionism in personality from a historical perspective. Psychological Bulletin, 1974, 81, 1026-1048.

Endler, N. S., \& Magnusson, D. Toward an interactional psychology of personality. Psychological Bulletin, 1976, 83, 956974.

Gage, N. L., \& Cronbach, L. J. Conceptual and methodological problems in interpersonal perception. Psychological Review, 1955, 62, 411-422.

GriffitT, W. Environmental effects on interpersonal affective behavior: Ambient effective temperature and attraction. Journal of Personality and Social Psychology, 1970, 15, 240-244.

GriffitT, W., \& Veitch, R. Hot and crowded: Influences of population density and temperature on interpersonal affective behavior. Journal of Personality and Social Psychology, 1971, 11, 92-98.

KaPLAN, M. F. Dispositional effects and weight of information in impression formation. Journal of Personality and Social Psychology, 1971, 18, 279-284. (a)

KAPLAN, M. F. The effect of evaluative dispositions, and amount and credibility of information on forming impressions of personality. Psychonomic Science, 1971, 24, 174-176. (b)

KaPLAN, M. F. The effect of judgmental dispositions in forming impressions of personality. Canadian Journal of Behavioral Science, 1971, 3, 43-51. (c)

KaPLAN, M. F. The modifying effect of stimulus information on the consistency of individual differences in impression formation. Journal of Experimental Research in Personality, 1972, 6, 213-219.

KaPLAN, M. F. Stimulus inconsistency and response dispositions in forming judgments of other persons. Journal of Personality and Social Psychology, 1973, 25, 58-64.

KAPLAN, M. F. Information integration in social judgment: Interaction of judge and informational components. In M. F. Kaplan \& S. Schwartz (Eds.), Human judgment and decision processes. New York: Academic Press, 1975.

KAPLAN, M. F. Measurement and generality of response dispositions in person perception. Journal of Personality, 1976, 44, 179-194.

Kaplan, M. F., \& Miller, L. E. Reducing the effects of juror bias. Journal of Personality and Social Psychology, 1978, 36, 1443-1455.

KELLEY, H. H. The warm-cold variable in first impression of persons. Journal of Personality, 1950, 18, 431-439.

KenRICK, D. T., \& Johnson, G. A. Interpersonal attraction in aversive environments: A problem for the classical conditioning paradigm? Journal of Personality and Social Psychology, 1979, 37, 572-579.

Porter, E. H. Pollyanna. Boston: Page, 1913.

Shaw, M. E., \& Wright, J. M. Scales for the measurement of attitudes. New York: McGraw-Hill, 1967.

Spielberger, C. D. Anxiety: State-trait-process. In C. D. Spielberger \& I. G. Sarason (Eds.), Stress and anxiety (Vol. 1). New York: Wiley, 1975.

Veitch, R., \& GRIfFitT, W. Good news-bad news: Affective and interpersonal effects. Journal of Applied Social Psychology, $1976,6,69-75$.

(Received for publication June 9, 1981.) 